\title{
A New Method to Determine a Reasonable Pile Spacing of Stabilizing Piles and Earth Pressure on Sheet Piles
}

\author{
Haiquan Zhang ${ }^{1,2}$, Jiangong Chen ${ }^{1,2, *}$, Huijuan $\mathrm{Ma}^{1,2}$, Zejun Yang ${ }^{1,2}$ and ${\mathrm{Hao} \mathrm{Li}^{3}}^{3}$ \\ ${ }^{1}$ College of Civil Engineering, Chongqing University, Chongqing 400045, China \\ ${ }^{2}$ Key Laboratory of New Technology for Construction of Cities in Mountain Area (Chongqing University), Ministry of Education, \\ Chongqing 400045, China \\ ${ }^{3}$ School of Civil Engineering, University of Leeds, Leeds, LS2 9JT, United Kingdom
}

Received 29 October 2018; Accepted 1 February 2019

\begin{abstract}
The soil arching effect is an important premise for non-continuity structures (e.g., stabilizing piles) to produce continuous retaining and masking effects; pile spacing is closely related to this concept. A scientific and reasonable method to determine the pile spacing and earth pressure on sheet piles is necessary to design safe and economically feasible stabilizing piles. At present, theoretical analyses of reasonable pile spacing rarely consider the influence of lateral earth pressure. This study proposes a new method to determine a reasonable pile spacing and earth pressure on sheet piles conforming to engineering practices. The said method considers the influence of lateral earth pressure. First, a mechanical analysis model of soil arching was established. In this model, the most unfavorable sections at the arch foot and arch top were used as a control condition, and the problem of soil arching of stabilizing piles was summarized as a zero-value problem to solve the nonlinear equations. Extrema were searched using MATLAB, through which a reasonable pile spacing and soil arching equation were determined. Second, the earth pressure on the sheet pile was calculated from the soil arching equation. Finally, the proposed method was proven reasonable by combining engineering cases. The results show that the pile spacing significantly varies under different failure control conditions of the soil arching effect. In the proposed method, the calculated pile spacing is $8 \mathrm{~m}$, which is between those obtained from two existing methods. This pile spacing is relatively reasonable. The earth pressure on the sheet pile is calculated by the integral method through a reasonable arch axis. The calculated soil range in the proposed method is closer to practice compared with those calculated via classical earth pressure theory and the original simplified granary method. Moreover, the earth pressure of the proposed method is appropriate. The proposed method is applicable to the design of sheet piles. Considering appropriate safety reserves, the proposed method can not only calculate the minimum pile spacing but also judge the reasonability of the designed pile spacing.
\end{abstract}

Keywords: soil arching effect, stabilizing piles, pile spacing, earth pressure

\section{Introduction}

Stabilizing piles are extensively applied in landslide control. Stabilizing piles can make full use of the soil arching effect and present some advantages in terms of construction cost compared with other control measures. Stabilizing piles have been proven an effective intervention measure in landslide control [1]. The soil arching effect produced by pile-soil interaction is an important premise for non-continuity supporting structures (e.g., stabilizing piles) to safely and economically produce a continuous self-supporting effect [2] The development of soil arching can effectively mobilize the stratum strength, which is significantly larger than the pile width, to resist pile sliding and improve the slide resistance of stabilizing piles. Pile spacing is the most important factor influencing the soil arching effect between piles. A reasonable stabilizing pile spacing is an important practical problem in slope engineering. The effective transmission of landslide thrust largely depends on the pile spacing. If the pile spacing is too large, the soil between piles slides out

*E-mail address: cig77928@126.com

ISSN: 1791-2377 @ 2019 Eastern Macedonia and Thrace Institute of Technology. All rights reserved. doi:10.25103/iestr.121.05 from the piles, and the project objectives will not be achieved. Conversely, stabilizing piles may resemble a retaining wall if the pile spacing is too small, and the shear strength of the sliding mass in front of the piles cannot be fully used. As a result, the construction cost and construction complexity increase. Therefore, a reasonable pile spacing is an important practical problem in engineering design. Studies on the influence of lateral earth pressure mainly hypothesize that loads above soil arching are uniformly distributed vertical loads; in these works, the horizontal loads are usually neglected [3]. Existing theoretical analyses on the reasonable spacing of stabilizing piles seldom consider the influence of the lateral earth pressure. A sheet pile between piles is often needed when the cantilever segment of a pile is free. In practical engineering, several methods are used to calculate the earth pressure on sheet piles, but no uniform agreement has yet been reached.

A mechanical model of a reasonable pile spacing was established based on the soil arching effect with consideration of the influence of the lateral earth pressure. Given a fixed reasonable arch axis, pile spacing, and arch height, the earth pressure on the sheet pile was determined using the integral method to provide a reference for practical engineering applications. 


\section{State of the Art}

The lateral stiffness of stabilizing pile embedment in landslides is significantly larger than that of the surrounding soil, and a rigid support boundary of the sliding soil is formed. Owing to the squeezing effect of the sliding soil, the relative rigidity difference between the pile and soil [4], as well as the relative deformation between the inter-pile soil and post-pile soil, forms the objective condition for the soil arching effect. The soil arching effect is a mechanical phenomenon in which the soil mass makes full use of its strength to adjust the internal stress distribution [5]. The soil arching effect caused by pile-soil interaction is an important reference for theoretical research on the reinforcement mechanism and design of stabilizing piles. In practical engineering, the reinforcement mechanism of stabilizing piles involves the transmission of the driving force of landslides onto stabilizing piles through the soil arching effect, thereby controlling landslides. Therefore, making full use of the soil arching effect of inter-pile soils, developing the bearing capacity of soil to the maximum extent, and determining a reasonable pile spacing are significant to the design of stabilizing piles.

The soil arching effect is universal in geotechnical engineering. Terzaghi [6] confirmed the existence of the soil arching effect by using a trap-door test. By viewing the pilereinforced embankment as a multi-trapdoor system, Rui [7] discussed the evolution mode of soil arching. Kahyaoglu [8] discovered from the simulation analysis of a bowl-shaped landslide that the pile deformation in the middle position is fairly large. Due to the soil arching effect, loads are transferred to piles with small deformation at their boundaries. Kahyaoglu [9] explored the influences of pile spacing and restraint at the pile head on deformation and stress transfer through an experiment and analyzed soil arching on the soil surface. Despite their novelty, however, previous experimental studies haven't analyzed further pile spacing influenced by the soil arching effect. The bearing capacity of piles and soil based on the soil arching effect can be fully used through geosynthetic reinforcements. Feng [10-11] evaluated and predicted the soil arching effect through theoretical analysis. However, these theoretical studies only focused on soil arching in the vertical direction. Qiu [12] analyzed the main influencing parameters of the soil arching effect through a numerical simulation including pile spacing, thickness of steady soil mass, embedment depth, and pile diameter. He [13] analyzed the order of key parameters influencing the soil arching effect in slopes reinforced by single or double rows of piles and determined the optimal combination of parameters for the design of stabilizing piles. Sharafi [14] carried out a numerical simulation of a slope reinforced by stabilizing piles and found that the strain wedge in front of piles can be used to describe soil arching; the influences of pile spacing on soil arching were also analyzed. These numerical simulations have not been quantitatively analyzed for reasonable pile spacing. Scholars have performed extensive analyses on the soil arching effect through experiments and theoretical and numerical simulations. Such analyses verified the existence of soil arching and analyzed the influencing factors of soil arching, as well as the stress transfer mechanism produced by pile-soil interaction. These studies facilitate the understanding of the soil arching effect and play a crucial role in promoting and enriching the related theory.

Many scholars have carried out continuous and extensive studies to determine pile spacing, and these studies have motivated advanced research on pile spacing. Wang [15] established a calculation formula of pile spacing according to the idea that the sum of the friction strength at two sides of the piles is no smaller than the landslide thrust between piles. However, the influence of the strength of soil arching on the pile spacing was not considered, resulting in relatively conservative results. Based on stress analysis of soil arching, Jiang [16] set up the corresponding calculation formula of pile spacing according to the Mohr-Coulomb strength criterion but neglected the static force equilibrium condition between piles, leading to high calculated results. Li [17] constructed a soil arching mechanical model based on the pile-soil interaction and deduced the governing equation of maximum pile spacing. This study, however, did not consider the combination of most unfavorable conditions, including the sectional strength at the arch foot and middle span of soil arching. Zhou [18] applied the static force equilibrium condition and strength failure of the arch foot as control conditions and hypothesized that the sliding resistance of soil in front arch is zero; however, this work neglected the landslide thrust undertaken by the pile back and directly transmitted by soil arching. Thus, the calculated pile spacing was too conservative. $\mathrm{Li}$ [19] and $\mathrm{Wu}$ [20] deduced a calculation formula of pile spacing based on friction soil arching but neglected the influence of lateral earth pressure. Considering basic control conditions, Xiao [21] determined pile spacing by introducing additional conditions such as calculated pile width and pile-soil deformation coordinating conditions. However, the influence of lateral earth pressure was not considered. Qiu [22] obtained the calculation formula of pile spacing based on a calculation model considering the combination of soil arching behind the pile and soil arching in the pile side. However, the influence of lateral earth pressure was not considered.

The calculation formulas of pile spacing were deduced in References [15-22]. These formulas only consider uniformly distributed loads behind the arch and neglect lateral earth pressure. No evident boundary occurs between soil arching and non-soil arching regions. Earth pressure on soil arching comes from squeezing of the surrounding soil, and the earth pressure may not exist in one direction alone. Such a simplified calculation formula is absolutely different from actual situations. In this study, aiming to achieve results close to those observed in practical engineering, the lateral earth pressure was enlisted into the study range. The combination of the most unfavorable conditions was considered by combining static force equilibrium conditions between piles and strength conditions of the mid-span section of soil arching and at the arch foot.

Pile spacing and the earth pressure on the sheet pile are influenced by many factors. No mature calculation method has yet been developed. Owing to the complexity and uncertainty of geotechnical properties, the design of stabilizing piles requires the vast experience of engineering technicians. Achieving safety and economic efficiency simultaneously is difficult. Hence, scientifically and reasonably determining the pile spacing and earth pressure on sheet piles have important safety and economic implications in the engineering design of stabilizing piles.

In this study, a mechanical model of reasonable pile spacing was established based on the soil arching effect with consideration of the effect of lateral earth pressure. A numerical computation was carried out by using MATLAB. The earth pressure on the sheet pile was calculated by using the integral method based on the determined reasonable pile 
Haiquan Zhang, Jiangong Chen, Huijuan Ma, Zejun Yang and Hao Li/

Journal of Engineering Science and Technology Review 12 (1) (2019) 37 - 44

spacing, arch height, and soil arching equation. This study aims to increase the reasonability of the stabilizing pile design, improve the utilization of sliding resistance in engineering, and verify the reasonability of the proposed method by combining engineering cases.

The remainder of this study is organized as follows. Section 3 introduces the construction process of a reasonable arch axis equation and control conditions for soil arching damage. The solution of the soil arching equation and calculation of the earth pressure on the sheet pile are also described. Section 4 verifies the reasonability and engineering applicability of the proposed theoretical analysis method by combining engineering cases. Section 5 provides the relevant conclusions.

\section{Methodology}

\subsection{Reasonable Arch Axis Equation}

In practical engineering, stabilizing piles are commonly rectangular and cylindrical in shape. To analyze stabilizing piles, the circular section can be replaced by an inscribed square. Rectangular piles are extensively applied in practical engineering. Using rectangular piles as the analysis object can not only simplify the discussion problems but also protect the universality of the research results [22].

The soil arching effect takes advantage of the good compressive performance and poor tensile properties of the soil mass. Soil arching is the result of self-optimization of stress after soil deformation, and, therefore, can be viewed as a reasonable arch axis under the hypothesis that landslide thrust is uniformly distributed in rock and soil masses between piles. In this study, the reasonable arch axis equation is deduced by natural equilibrium arch theory with consideration of lateral earth pressure.

\subsubsection{Basic hypothesis of the calculation model}

(1) The soil arching effect occurs on the sheet pile wall structure. The end-bearing soil arching developed behind piles is considered, and the weak friction soil arching between two piles is neglected.

(2) The soil weight in the soil arching region is not considered; thus, the soil arching effect is constant despite changes in buried depth. One plane above the sliding surface is chosen as the research object, and the soil arching problem is simplified as a plain strain problem.

(3) Under failure of the natural equilibrium arch, the soil arching is damaged when the soil arching stress state meets one of the following two conditions: (a) the arch foot fails, i.e., the triangular compression zone formed by two adjacent arches at the back of the piles fails, or (b) the section at the arch top fails.

\subsubsection{Force equilibrium equation of the natural equilibrium arch}

Soil arching at a unit height along the buried depth of piles was analyzed according to the above hypothesis. A simplified calculation model of soil arching between adjacent piles is shown in Fig. 1. Here, $b$ is the width of the pile cross-section, and $a$ is the net spacing of adjacent piles. The pressure arch curve under the width of the pile crosssection $b$, the net distance of adjacent piles $a$, the intensity of the landslide thrust $q$, and the intensity of the lateral load $(\lambda q)$ result in natural equilibrium soil arching. The vector height of the arch is $f$, and $\lambda$, the coefficient of the lateral earth pressure, can be calculated according to the static earth pressure coefficient: $\lambda=\mathrm{k}_{0}=\boldsymbol{v} / \mathbf{1 - v}$, where $\boldsymbol{v}$ is Poisson's ratio. Owing to the difficulty of measuring the Poisson's ratio of soil, this parameter is approximately calculated as $\lambda \approx 1-\sin \phi$.

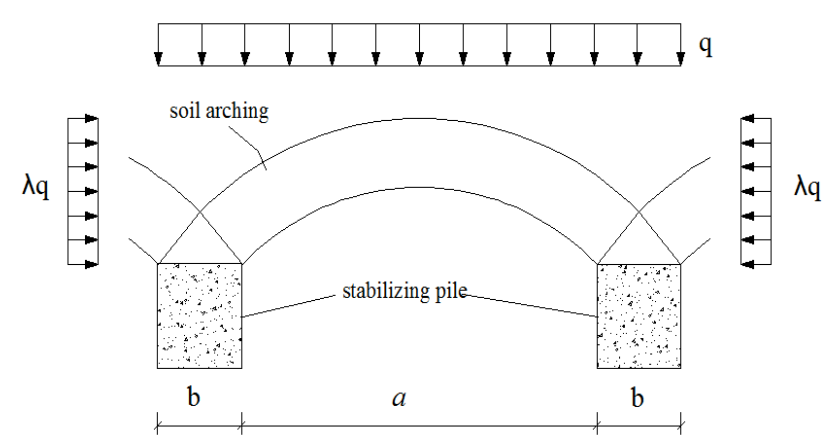

Fig. 1. Layout of stabilizing piles and soil arching

A simplified stress diagram of natural equilibrium soil arching is shown in Fig.2. Due to the arch shape and stress symmetry, the arch is divided in the middle. The OM section from the left semi-arch is collected for study, and a horizontal thrust (T) transmitted from the right semi-arch is applied to point O. Load $q$ is uniformly distributed behind the arch, and load $\lambda \mathrm{q}$ is uniformly distributed at the sides of the arch. Since the compressive strength of the soil is significantly higher than its tensile strength, the form of the pressure arch can be viewed as the best natural equilibrium form without shear forces and bending moments. Therefore, only an axial pressure (W) occurs at point M. According to the stress equilibrium at different points of stable soil arching, the forces at point $\mathrm{M}$ chose the equilibrium equation of moment:

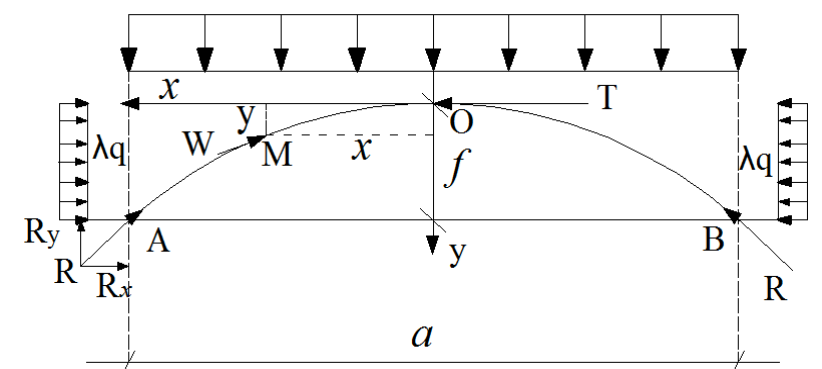

Fig. 2. Stress diagram and coordinates of the natural equilibrium arch

$$
\frac{q x^{2}}{2}+\frac{\lambda q y^{2}}{2}-T y=0
$$

Considering the force equilibrium equation of the entire left semi-arch along the $\mathrm{X}$ direction:

$$
T=\lambda q f+R_{x}
$$

Considering the stress equilibrium equation of the entire left semi-arch along the $\mathrm{Y}$ direction:

$$
R_{y}=\frac{q a}{2}
$$

For the left semi-arch, the moment of point $\mathrm{O}$ is:

$R_{x} f-R_{y} \frac{a}{2}+\frac{\lambda q f^{2}}{2}+\frac{q a^{2}}{8}=0$ 
Substituting Eq.(3) into Eq.(4) gives:

$R_{x}=\frac{q a^{2}}{8 f}-\frac{\lambda q f}{2}$

$\mathrm{R}_{\mathrm{x}}$ and $\mathrm{R}_{\mathrm{y}}$ are components of the reaction force $(R)$ at the arch foot along the $\mathrm{X}$ and $\mathrm{Y}$ directions, respectively.

Substituting Eq.(2), Eq.(4), and Eq.(5) into Eq.(1), the natural arch equation is obtained:

$\frac{x^{2}}{(B \sqrt{\lambda})^{2}}+\frac{(y-B)^{2}}{B^{2}}=1$

Where

$B=\frac{f}{2}+\frac{a^{2}}{8 \lambda f}$

Eq.(6) shows that the shape of the natural equilibrium arch forms one part of the elliptic curve. The length of the semi-axis of this elliptic curve along the $\mathrm{X}$ direction is $B \sqrt{\lambda}$, and the length of the semi-axis of the elliptic curve along the $\mathrm{Y}$ direction is $B$. The coordinates of the center point of the elliptic curve are $(0, \mathrm{~B})$, and this center point is below the connecting line $A B$.

\subsection{Control conditions of soil arching failure}

\subsubsection{Failure of the arch foot as the control condition}

For the conditions of soil arching to be fully developed, the two adjacent arches of a triangle compression zone are generally believed to be formed behind piles. The arch foot includes three parts (Fig.3): (I) is the pile body at the soil arch foot that supports the component, (II) is the triangular compression zone of the soil mass behind the piles, and (III) is the transition zone between the arch foot and arch body.

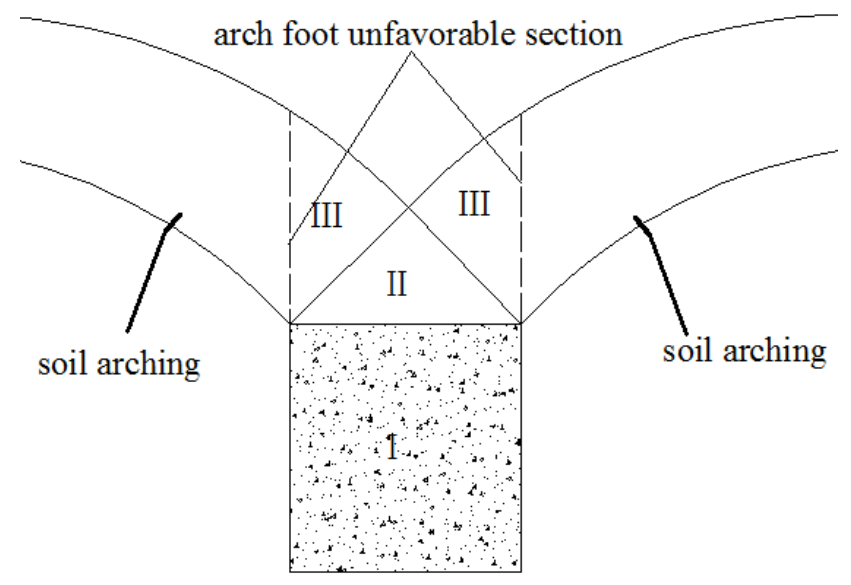

Fig. 3. Zoning of the arch foot

Based on the zoning of the arch foot transition in Fig.4, the respective components of the section at the border between the transition and triangular compression zones along the $\mathrm{X}$ and $\mathrm{Y}$ directions are:

$R_{o x}=\frac{(a+b)^{2}}{8 f}-\frac{\lambda q f}{2}$

$R_{o y}=\frac{q(a+b)}{2}$

$$
\tan \alpha=\frac{R_{o x}}{R_{o y}}
$$

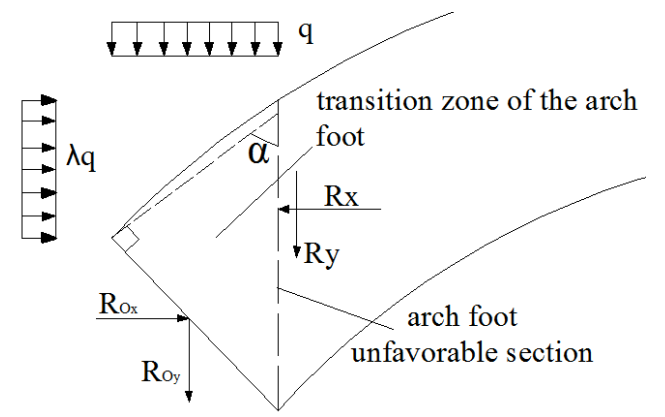

Fig. 4. Stress analysis during arch foot transition

In the triangular compression zone behind piles, the resultant force at the border between the transition and triangular compression zones is hypothesized to be perpendicular to the section (Fig.5).

Substituting Eq.(8) and Eq.(9) into Eq.(10) yields:

$\tan \alpha=\frac{a+\mathrm{b}}{4 f}-\frac{\lambda f}{a+\mathrm{b}}$

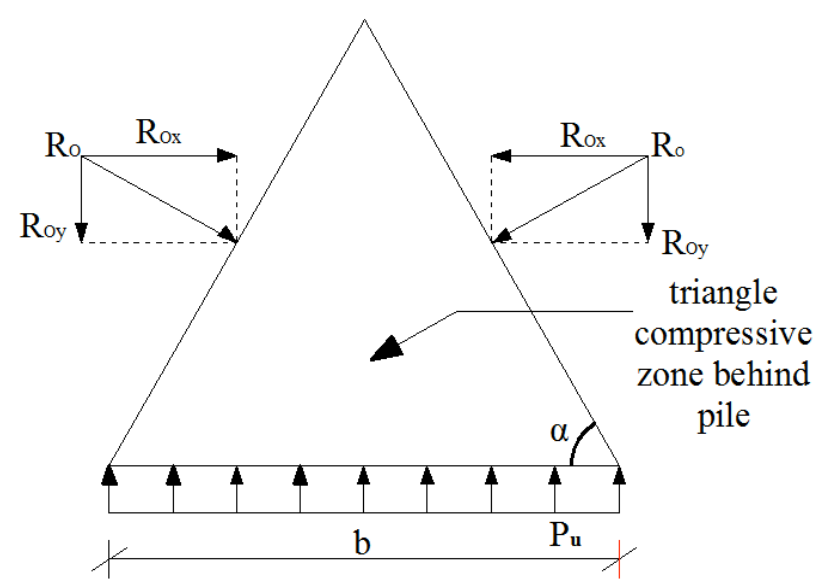

Fig. 5. Stress analysis of the soil mass in the triangular compression zone behind piles

Under this circumstance, the reaction force provided by the pile is:

$p_{u}=\frac{q(a+b)}{b}$

The compressive stresses at two sides of the triangle compression zone are:

$\sigma=\frac{\sqrt{R_{\mathrm{ox}}^{2}+R_{\mathrm{oy}}^{2}}}{t}=\frac{2 \sqrt{R_{\mathrm{ox}}^{2}+R_{\mathrm{oy}}^{2}} \cos \alpha}{b}=\frac{2 R_{\mathrm{oy}}}{b}=\frac{q(a+b)}{b}$

where $t$ is the thickness of the soil arch, i.e., $\mathrm{t}=\mathrm{b} / 2 \cos \alpha$, and $\alpha$ is the angle between one side of the triangular compression zone and the horizontal direction.

Eq.(12), Eq.(13), and the symmetry observed show that, given the same compressive stress at boundary of the triangular compression zone, all points in this zone are static earth pressure, i.e., the ultimate stable state. Therefore, the above hypothesis is reasonable. 
Haiquan Zhang, Jiangong Chen, Huijuan Ma, Zejun Yang and Hao Li/

Journal of Engineering Science and Technology Review 12 (1) (2019) 37 - 44

According to the condition for failure of the arch foot, the unfavorable section meets the Mohr-Coulomb strength criterion. Considering the safety factor $(\mathrm{K})$, it gets:

$$
K R_{\mathrm{y}}=R_{\mathrm{x}} \tan \phi+\mathrm{cb} / \sin 2 \alpha
$$

\subsubsection{Failure of the arch top as the control condition}

Fig.6 shows that, when the unfavorable section at the arch top is at the ultimate equilibrium state, the compressive stress displays a trapezoidal distribution, where

$$
\begin{aligned}
& \sigma_{\max }=q \tan ^{2}\left(45^{\circ}+\phi / 2\right)+c \tan \left(45^{\circ}+\phi / 2\right) \\
& \sigma_{\min }=c \tan \left(45^{\circ}+\phi / 2\right)
\end{aligned}
$$

The ultimate total pressure at the section is:

$$
T_{\max }=\frac{q b \tan ^{2}\left(45^{\circ}+\phi / 2\right)+2 \mathrm{cb} \tan \left(45^{\circ}+\phi / 2\right)}{4 \cos \alpha}
$$

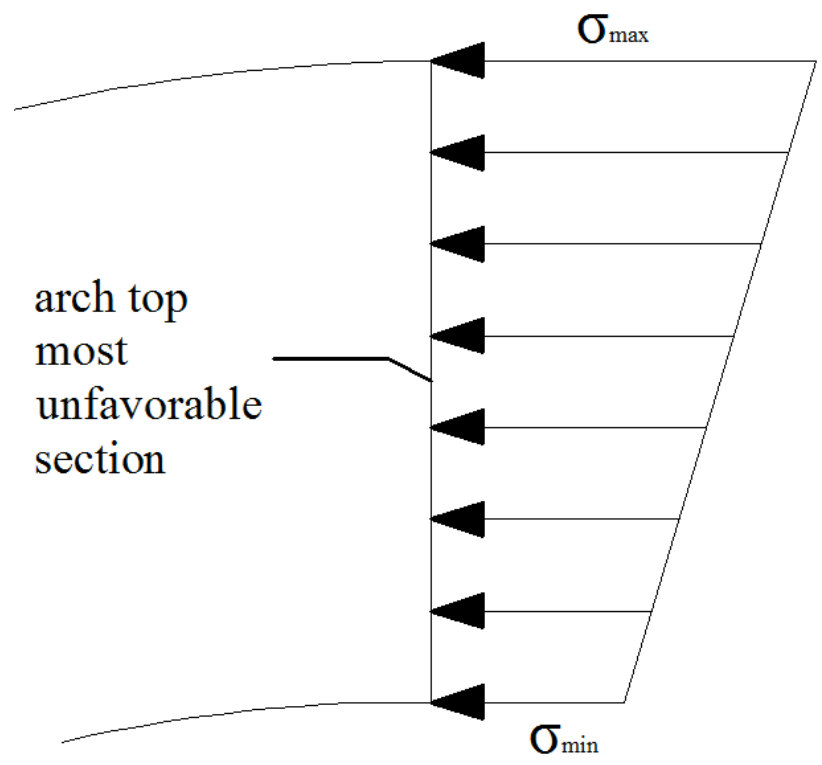

Fig. 6. Stress distribution on the section at the arch top

Considering the safety factor $\mathrm{K}$, the condition for failure of the arch top is:

$\mathrm{KT}=\mathrm{T}_{\max }$

3.3 Determining a reasonable pile spacing of stabilizing piles based on the natural equilibrium arch Substituting Eq.(8) and Eq.(9) into Eq.(10) yields:

$\Phi_{1}=\tan \alpha+\frac{\lambda f}{a+b}-\frac{a+b}{4 f}=0$

Substituting Eq.(3) and Eq.(5) into Eq.(14) yields:

$\Phi_{2}=\left(\frac{\mathrm{q} a^{2}}{4 f}-\lambda q f\right) \tan \phi+\frac{2 \mathrm{cb}}{\sin 2 \alpha}-\mathrm{K} q a=0$

Substituting Eq.(8), Eq.(10), and Eq.(11) into Eq.(11) yields:
$\Phi_{3}=\frac{q b \tan ^{2}\left(45^{\circ}+\phi / 2\right)+2 \mathrm{cb} \tan \left(45^{\circ}+\phi / 2\right)}{4 \cos \alpha}$

$-K\left(\mathrm{q} a^{2} / 8 f+\lambda \mathrm{q} f / 2\right)$

Therefore, the soil arching problem of stabilizing piles can be summarized as a problem requiring the solution of three unknown variables, namely, the net spacing of adjacent piles $(a)$, the angle between the triangular compression zone and the horizontal direction $(\alpha)$, and the arch height ( $f$ ). These variables meet the above three nonlinear equations, and the problem is equal to a zero-value problem of solving the following function $\Phi(a, \alpha, f)$.

$\Phi(a, \alpha, f)=\Phi_{1}^{2}+\Phi_{2}^{2}+\Phi_{3}^{2}=0$

The solution of Eq.(22) can be obtained by solving the minimum ( 0 ) value of function $\Phi$. When the minimum of $\Phi$ is not zero, controlling landslides by using stabilizing piles under the given pile width and landslide thrust is inappropriate.

Geological investigation data are mastered through a field survey on landslide control, and values of the physical and mechanical indices (c, $\phi)$ of the rock and soil masses on the landslide and landslide thrust $(q)$ given by the investigation report are studied. The functional module $\Phi(a, \alpha, f)$ is set up by the function provided by MATLAB, and an initial value is given and substituted into the corresponding parameters. If the initial value is reasonable (generally, $a=3 \mathrm{~b}, f=a / 3$, and $\alpha=\phi$ ), the minimum value of the function can be quickly found. Independent variables $(a, \alpha, f)$ that allow the function $\Phi(a, \alpha, f)$ to reach the minimum value can be calculated according to Eq.(22), thereby enabling determination of a reasonable pile spacing and soil arching equation.

The pile spacing is: $l=a+b$.

The soil arching equation is: $x^{2} /(B \sqrt{\lambda})^{2}+(y-B)^{2} / B^{2}=1$, where $B=f / 2+a^{2} / 8 \lambda f$.

\subsection{Calculation formula of the earth pressure on the sheet pile}

A sheet pile between adjacent piles is set at one side of the front free-face of the piles. Considering the soil arching effect, a sheet pile between adjacent piles can be simplified as a side wall of a slio composed of piles, soil arching, and sheet piles between piles. The thrust on the sheet pile is then calculated. Compared with the traditional simplified granary method, the soil arching shape applies the actual arch axis but does not simplify it into a triangle. The stress range of the sheet pile conforms better to practical situations. The stress state of simplified granary method is analyzed (Fig.7) to obtain the calculation formula for the horizontal earth pressure on the side wall:

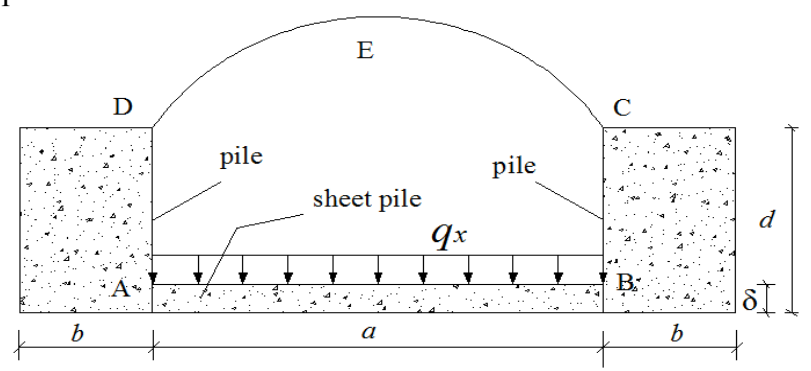

Fig. 7. Sketch of the simplified granary method 
Haiquan Zhang, Jiangong Chen, Huijuan Ma, Zejun Yang and Hao Li/

Journal of Engineering Science and Technology Review 12 (1) (2019) 37 - 44

$$
\mathrm{q}_{\mathrm{x}}=\frac{A \gamma}{P \tan \phi}\left(1-\mathrm{e}^{-\frac{P}{A} \mathrm{kz}}\right)
$$

where $q_{x}$ is the horizontal thrust of the soil between piles toward the sheet pile;

$A$ is the area of ABCDE;

$$
A=a(d-\delta)+2 B \int_{\theta_{0}}^{\pi / 2} \sqrt{\lambda \sin ^{2} \theta+\cos ^{2} \theta} d \theta
$$

where $\theta_{0}=\arccos \left(\frac{a}{2 B \sqrt{\lambda}}\right)$;

$P$ is the perimeter of the enclosed section $A B C D E$;

$P=2(d-\delta)+2 a \int_{\theta_{0}}^{\pi / 2} \sin \theta(B-f-B \sin \theta)=2(d-\delta) ;$

$+2 a\left[\sin 2 \theta_{0} / 4+(B-f) \cos \theta_{0}+B \theta_{0} / 2-\pi B / 4-B+f\right]$

$\lambda$ is the soil weight of the landslide body;

$\phi$ is the internal frictional angle of the landslide body;

$\mathrm{z}$ is the depth from the calculation point to the pile top;

$\mathrm{d}$ is the side length of the pile parallel to the horizontal landslide thrust direction;

$\delta$ is the thickness of the sheet pile;

$k=\tan \phi \tan ^{2}(\pi / 4-\phi / 2)$.

The solution of the calculation formula of the earth pressure on the sheet pile is based on a reasonable arch axis, pile spacing, and arch height. Through accurate integration of soil range in which the sheet pile produces earth pressure, the earth pressure on the sheet pile based on the soil arching effect could be calculated by bringing in relevant parameters.

\section{Result and Discussion}

1. Middle and late Pleistocene loess-like deposits are the main components of the slope of a road segment. The lower lithology is dense and composed of hard yellowish-brown and reddish loess-like clay, while the landslide body is mainly composed of Xiashu clay. The cohesion is $c=40 \mathrm{kPa}$, the internal frictional angle is $\phi=35^{\circ}$, and $\lambda=18 \mathrm{kN} / \mathrm{m}^{3}$. According to engineering requirements, $\mathrm{K}$ was set to 1.2 . The designer chose landslide control by cantilever stabilizing piles. At positions with stabilization, the landslide thrust behind the pile was $Q=640 \mathrm{kN} / \mathrm{m}$, and the length of the cantilever section was $\mathrm{H}=8.0 \mathrm{~m}$. Therefore, the thrust in unit height along the pile length was $\mathrm{q}=\mathrm{Q} / \mathrm{H} \times 1=80$ $\mathrm{kN} / \mathrm{m}$. The sectional height and width of the pile were $d=3$ $\mathrm{m}$ and $b=2 \mathrm{~m}$, respectively. The maximum pile spacing was determined.

(1) Determination of pile spacing
The relevant parameters above were brought into the calculation formula of pile spacing in Reference 18. The formula calculated that $a=5.65 \mathrm{~m}$. Considering safety reserves, the formula calculated that $a=5.65 / 1.2=4.63 \mathrm{~m}$.

The calculated results of the proposed method of pile spacing are listed in Table 1.

Table 1. Calculated results of soil arching between piles and pile spacing

\begin{tabular}{c|c}
\hline Arch axis equation & $\frac{x^{2}}{6.874^{2}}+\frac{(y-10.527)^{2}}{10.527^{2}}=1$ \\
\hline $\begin{array}{c}\text { Soil arching } \\
\text { parameters }\end{array}$ & $a=6.492 \mathrm{~m}, f=1.248 \mathrm{~m}$, and $\alpha=58.6^{\circ}$ \\
\hline
\end{tabular}

The results in Table 1 were all calculated when soil arching was at the ultimate state. By comparison, when the soil arching effect was considered with different failure control conditions, the pile spacing values varied significantly. In Reference 15, lateral friction undertook the total landslide thrust between piles, which was used as the equilibrium force system, without consideration of the influence of the soil arching strength on the pile spacing. Therefore, the calculated results were relatively high. In Reference 18, the force equilibrium condition and failure of the arch foot strength were used as control conditions. The shear strength of soil in the region in front of the arch was hypothesized to be zero, but the landslide thrust undertaken by the pile back and transmitted by end-bearing soil arching could be neglected. Obviously, the calculated result of pile spacing is very conservative and only 2.3 times that of the pile width. In the calculation model of pile spacing in this study, attention was given to stable end-bearing soil arching with a high bearing capacity. Here, the most unfavorable sections at the arch foot and arch top were used as the control condition for reasonable pile spacing. The extreme can be searched quickly by MATLAB. Considering appropriate safety reserves, this method can not only calculate the minimum pile spacing but also judge the reasonability of the designed pile spacing. The calculated results in this study were between those of the two existing methods. Hence, the net pile spacing should be $6.492 \mathrm{~m}$, and the pile central distance should be $\mathrm{L}=a+b=8.492 \mathrm{~m}$. These figures are convenient for construction and consider the safety reserves of slopes in the engineering design of sheet piles. A reasonable pile spacing between adjacent piles is $8 \mathrm{~m}$.

(2) Design value of earth pressure on sheet pile

In consideration of the reasonable and relatively large pile spacing $(8 \mathrm{~m})$ and the long cantilever section of the stabilizing piles, the sheet pile should be set between adjacent piles to prevent local landslide and improve sliding resistance. The earth pressure on the sheet pile was calculated and compared by using the original simplified granary method (standard method), the proposed method, and classical earth pressure theory. The related results are shown in Tables 2, 3, and 4.

Table 2. Calculated results of earth pressure on the sheet pile in the original simplified granary method

\begin{tabular}{c|c|c|c|c|c|c|c|c}
\hline $\begin{array}{c}\text { Calculation parameters of earth pressure } \\
\text { on sheet pile }\end{array}$ & \multicolumn{2}{|c|}{$\begin{array}{l}\text { Assuming a sectional area in soil arching A }=30.03 \mathrm{~m}^{2} \text { and length of the inner boundary of the arch } \\
P=21.67 \mathrm{~m} \text {, the calculation formula of earth pressure on the sheet pile: } q_{x}=35.616\left(1-\mathrm{e}^{-0.137 z}\right)\end{array}$} \\
\hline $\begin{array}{c}\text { Depth of the calculation point } \mathrm{z} / \mathrm{m} \\
\text { Earth pressure on sheet pile } \mathrm{kPa}\end{array}$ & 1 & 2 & 3 & 4 & 5 & 6 & 7 & 8 \\
\hline
\end{tabular}


Haiquan Zhang, Jiangong Chen, Huijuan Ma, Zejun Yang and Hao Li/

Journal of Engineering Science and Technology Review 12 (1) (2019) 37 - 44

Table 3. Calculated results of earth pressure on the sheet pile in the proposed method

\begin{tabular}{|c|c|c|c|c|c|c|c|c|}
\hline \multirow{2}{*}{$\begin{array}{l}\text { Calculation parameters of earth } \\
\text { pressure on the sheet pile } \\
\text { Depth of the calculation point } \mathrm{z} / \mathrm{m}\end{array}$} & \multicolumn{8}{|c|}{$\begin{array}{l}\text { Assuming a sectional area in soil arching } \mathrm{A}=25.92 \mathrm{~m}^{2} \text { and length of inner boundary of } \operatorname{arch} P=10.96 \mathrm{~m} \text {, the } \\
\text { calculation formula of earth pressure on the sheet pile: } q_{x}=60.786\left(1-\mathrm{e}^{-0.08 z}\right)\end{array}$} \\
\hline & 1 & 2 & 3 & 4 & 5 & 6 & 7 & 8 \\
\hline Earth pressure on the sheet pile $\mathrm{kPa}$ & 4.69 & 9.01 & 13.00 & 16.69 & 20.09 & 23.23 & 26.12 & 28.80 \\
\hline
\end{tabular}

Table 4. Calculated results of earth pressure on the sheet pile in classical earth pressure theory

\begin{tabular}{|c|c|c|c|c|c|c|c|c|}
\hline \multirow{2}{*}{$\begin{array}{l}\text { Calculation parameters of earth pressure on } \\
\text { the sheet pile } \\
\text { Depth of calculation point } \mathrm{z} / \mathrm{m}\end{array}$} & \multicolumn{8}{|c|}{$\begin{array}{c}\text { Rankine earth pressure coefficient } \mathrm{k}=\tan ^{2}\left(45^{\circ}-\phi / 2\right) \\
\text { Calculation formula of earth pressure on the sheet pile: } q_{x}=\gamma z k\end{array}$} \\
\hline & 1 & 2 & 3 & 4 & 5 & 6 & 7 & 8 \\
\hline Earth pressure on sheet pile $\mathrm{kPa}$ & 4.87 & 9.74 & 14.61 & 19.48 & 24.35 & 29.22 & 34.09 & 38.96 \\
\hline
\end{tabular}

Calculated results in Tables $2-4$ and the variation curves of earth pressure on the sheet pile in Fig.8 were compared.

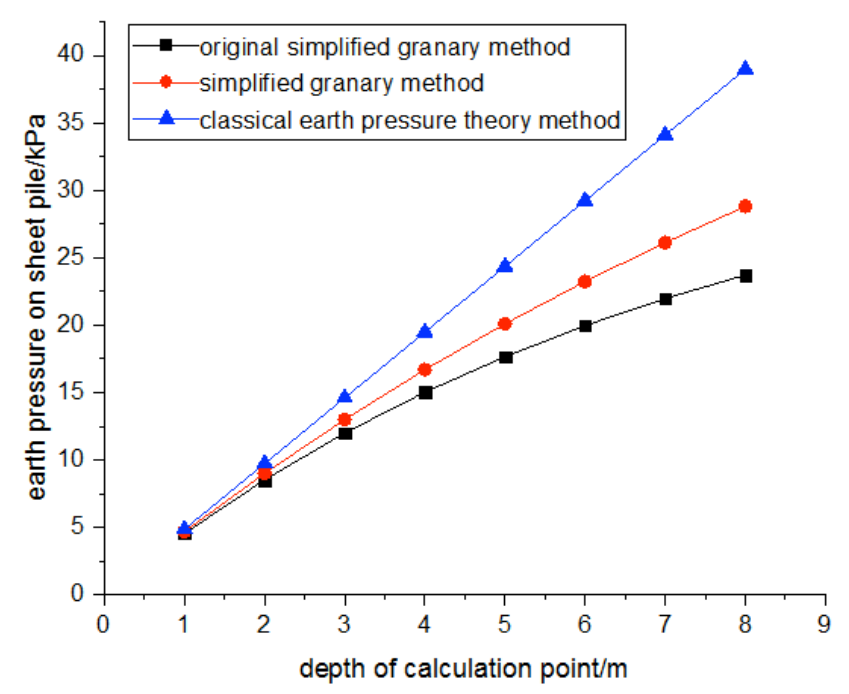

Fig. 8. Relation of the earth pressure on the sheet pile and depth

The results of all three-calculation methods were similar close to the pile top. As buried depth increased, differences in earth pressure increased accordingly. The earth pressure on the sheet pile calculated by using classical earth pressure theory according to the total earth pressure was the highest amongst the values obtained when the influence of the soil arching effect is not considered. The design of the sheet pile is too conservative based on the earth pressure on sheet pile calculated by using classical earth pressure theory. The original simplified granary method hypothesizes that the arch axis is a right-angled isosceles triangle that uses the net pile spacing as the hypotenuse. The sheet pile undertook the earth pressure at the front of the arch, thereby resulting in the lowest calculated results. The improved simplified granary method in this study calculates the area and perimeter of the soil in the arch by using the integral method based on a reasonable arch axis. The soil range on the sheet pile is realistic, and the corresponding earth pressure is moderate, thereby indicating that the proposed method can reasonably reflect the earth pressure on the sheet pile between two adjacent piles. The proposed method is appropriate for application to the design of sheet piles.

2. The lowest level of the cut slope on a highway in the north region of Sichuan Province is a cantilever-stabilizing pile-reinforced slope. The average weight of the landslide behind the pile is $\gamma=20 \mathrm{kN} / \mathrm{m}^{3}$, and the cohesion of the fast shear strength is $c=50 \mathrm{kPa}$. The internal frictional angle,
Poisson's ratio, and deformation modulus are $\phi=28^{\circ}$, 0.3 , and $60 \mathrm{MPa}$, respectively. Piles were poured using C30 concrete. The front and side widths of the cross section were $\mathrm{b}=2 \mathrm{~m}$ and $a=3 \mathrm{~m}$, respectively, the total length of the pile was $22 \mathrm{~m}$, and the length of the cantilever section was $h_{1}=$ $11 \mathrm{~m}$. The landslide thrust behind the pile was calculated as $\mathrm{E}=1050 \mathrm{kN} / \mathrm{m}$ by using the transfer coefficient method. The thrust component in unit height along the length of the pile was $q=E / h_{1}=95.5 \mathrm{kN} / \mathrm{m}$. Based on engineering requirements, the safety reserve needs to be considered. Thus, $\mathrm{K}$ was set to 1.3 .

The pile spacing was calculated as $6.97 \mathrm{~m}$ by using the method of Liangwei Jiang, $2.93 \mathrm{~m}$ by using the method of Peide Zhou, $8 \mathrm{~m}$ by using the method of Changdong Li, 4.79 $\mathrm{m}$ by using the method of Yinghua Zhou, and $5.63 \mathrm{~m}$ by using the proposed method. The pile spacing $(6 \mathrm{~m})$ in practical engineering ensures good stability of the constructed slope. Thus, the pile spacing calculated by the proposed method is closer to the practical value than those obtained from other methods.

\section{Conclusions}

To obtain a reasonable pile spacing and earth pressure on sheet piles conforming to engineering standards, the gap between theory and practice should be narrowed. In this study, the cantilever-stabilizing pile with sheet piles was studied. Based on the soil arching effect, a new method to calculate pile spacing and the earth pressure on the sheet pile was proposed. The influence of lateral earth pressure was considered when determining a reasonable pile spacing to comprehensively reflect the actual situation and produce calculated results conforming to engineering standards. The major conclusions of this work are as follows.

(1) The influence of lateral earth pressure must be considered to determine a reasonable pile spacing between adjacent stabilizing piles. Pile spacing is suggested to be controlled according to static equilibrium conditions between piles and the strength of sections at the arch foot and at the mid-span of soil arching. The combination of the most unfavorable conditions is considered to produce calculated results that conform to engineering standards.

(2) Under the condition that soil arching can be fully developed, the arch foot is divided into three parts. (a) the pile body at the soil arching foot that supports the component, (b) the compression zone of the pile head, and (c) the transition zone between the arch foot and arch body 
Haiquan Zhang, Jiangong Chen, Huijuan Ma, Zejun Yang and Hao Li/

\section{Journal of Engineering Science and Technology Review 12 (1) (2019) 37 - 44}

determining the position of the most unfavorable section. Based on the analysis of the triangular compression zone, all points in this zone are at the hydrostatic pressure state. Thus, they are all at an extremely stable state, which proves the reasonability of the hypothesis.

(3) The calculation formula of a reasonable arch axis is deduced by establishing a mechanical model of soil arching. Results demonstrate that soil arching forms one part of the elliptic curve. This method can not only calculate the minimum of pile spacing but also judge the reasonability of the designed pile spacing.

(4) Existing calculation formulas of pile spacing are compared with the proposed calculation method by combining engineering cases. Results show that the proposed calculation method of pile spacing yields reasonable results. When calculating the earth pressure on a sheet pile, the soil arching calculated by the proposed simplified granary method is an actual arch axis and does not simplify the triangle. The calculated soil range on the sheet pile is closer to practical situations compared with those determined from classical earth pressure theory and the traditional simplified granary method. The earth pressure calculated by the proposed method is between those determined from the two methods. This result reveals that the proposed calculation method of earth pressure considering the soil arching effect can increase the economic efficiency and accuracy of sheet pile design.

In summary, the proposed theoretical analysis method can determine a reasonable pile spacing and earth pressure on sheet piles. Programmed numerical computation based on MATLAB is easy and takes the influences of the soil arching effect and lateral earth pressure into account, thereby conforming to practical situations. The proposed method presents a certain engineering application value. The proposed method also hypothesizes that soil arching is distributed uniformly along the length of a pile, which differs from the practical situation to some extent. This finding should be further investigated in future studies.

\section{Acknowledgements}

The study was supported by the Major Program of the National Natural Science Foundation of China (No. 51638002).

This is an Open Access article distributed under the terms of the Creative Commons Attribution License

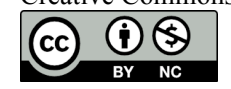

\section{References}

1. He Y, Hazarika H, Yasufuku N, et al. "Estimation of lateral force acting on piles to stabilize landslides". Natural Hazards, 79(3), 2015, pp. 1981-2003.

2. Keawsawasvong S, Ukritchon B. "Undrained limiting pressure behind soil gaps in contiguous pile walls". Computers and Geotechnics, 83, 2017, pp. 152-158.

3. Chen Z, He P, Yan D, et al. "A method to calculate the rational spacing between pipe roofs considering soil arching effects"[J].Rock and Soil Mechanics, 40(5) ,2018, pp.1-8.

4. Zhao L, Zhou W, Geng X, et al. "A closed-form solution for columnsupported embankments with geosynthetic reinforcement". Geotextiles and Geomembranes, 2019.

5. Pardo G S, Sáez E. "Experimental and numerical study of arching soil effect in coarse sand". Computers and Geotechnics, 57, 2014, pp. 75-84.

6. Terzaghi K. "Theoretical soil mechanics". New York: John Wiley \& Son, 1943.

7. Rui R, van Tol F, Xia Y, et al. "Evolution of soil arching: 2D analytical models". International Journal of Geomechanics, 18(6), 2018, pp. 1-15.

8. Kahyaoğlu M R, İmançlı G, Özden G, et al. "Numerical simulations of landslide-stabilizing piles: a remediation project in Söke, Turkey". Environmental Earth Sciences, 76(19), 2017, pp. 643-656.

9. Mehmet Rifat Kahyaoğlu, Okan Onal, Gökhan Imançlı, "Gürkan Ozden, Arif Ş. Kayalar. Soil arching and load transfer mechanism for slope stabilized with piles". Journal of Civil Engineering and Management, 18(5), 2012, pp.701-708.

10. Feng S, Ai S, Chen H. "Estimation of arching effect in geosynthetic-reinforced structures". Computers and Geotechnics, 87, 2017, pp.188-197.

11. Feng S, Ai S, Chen H, et al. "An analytical method for predicting load acting on geosynthetic overlying voids". Geotextiles and Geomembranes, 45(6), 2017, pp.570-579.

12. Qiu H, Fu S. "Study on load-bearing mechanism of stabilizing pilegroups by FEM and its application". Applied Mechanics \& Materials, 638, 2014, pp.656-670.
13. He G F, Li Z G, Yuan Y, et al. "Optimization analysis of the factors affecting the soil arching effect between landslide stabilizing piles". Natural Resource Modeling, 31(2), 2018, pp. 1-21.

14. Sharafi H, Sojoudi Y. "Experimental and numerical study of pilestabilized slopes under surface load conditions". International Journal of Civil Engineering, 14(4), 2016, pp.221-232.

15. Wang C, Chen L, "Lin L. Soil Arch Mechanical Character and Suitable Space between One Another Anti-sliding Pile".Journal of Mountain Science, 19, 2010, pp.556-559.

16. Jiang L, Huang R, "Jiang Z.Analysis of Soil Arching Effects between Adjacent Piles and Their Spacing in Cohesive Soils". Rock and Soil Mechanics, 27(3), 2006, pp.445-450.

17. Li S J, Chen J, Feng X T. "Analytic solution to soil arching effect and its application based on interaction of slope soil and piles". Materials Research Innovations, 15(sup1), 2011, pp. 578-581.

18. Zhou Y, Zhou D, Feng J. "Geometrically mechanical characters of soil arch between two adjacent laterally loaded piles and determination of suitable pile spacing". Rock and Soil Mechanics, 27, 2006, pp.455-457.

19. Li C, Wu J, Tang H, et al. "A novel optimal plane arrangement of stabilizing piles based on soil arching effect and stability limit for 3D colluvial landslides”. Engineering Geology, 195, 2015, pp.236247.

20. Wu J, Li C, Liu Q, et al. Optimal isosceles trapezoid cross section of laterally loaded piles based on friction soil arching". KSCE Journal of Civil Engineering, 21(7), 2017, pp. 2655-2664.

21. Xiao S, Cheng F. "Further discussion on calculation method of rational spacing between two adjacent cantilever piles for stabilizing slope". Rock and Soil Mechanics, 36(1), 2015, pp.111116.

22. Qiu Z, Han T, Dou H, et al. "Analysis of Spacing between Antislide Piles Considering Soil Arch on Lateral Sides and Back". Journal of Zhejiang University (Engineering Science), 50(3), 2016, pp.559. 